\title{
CROMATOGRAFIA EM LEITO MÓVEL SIMULADO NA PRODUÇÃO DE SUBSTÂNCIAS ENANTIOMERICAMENTE PURAS OU ENRIQUECIDAS EM LARGA ESCALA
}

Ivanildo José da Silva Junior, Vinícius de Veredas, Marco Antônio Garcia dos Santos e Cesar Costapinto Santana

Departamento de Processos Biotecnológicos, Faculdade de Engenharia Química, Universidade Estadual de Campinas, CP 6066, 13083-970 Campinas - SP, Brasil

Marcos José Souza Carpes e Carlos Roque Duarte Correia*

Instituto de Química, Universidade Estadual de Campinas, CP 6154, 13084-971 Campinas - SP, Brasil

Recebido em 28/6/05; aceito em 8/11/05; publicado na web em 18/5/06

\begin{abstract}
SIMULATED MOVING BED CHROMATOGRAPHY IN THE PRODUCTION OF ENANTIOMERICALLY PURE OR ENRICHED COMPOUNDS IN LARGE SCALE. There is great interest nowadays in the use of preparative liquid chromatography as an effective tool for the production of enantiomerically pure, or enriched, compounds for the pharmaceutical industry. To make the chromatographic process economically attractive, attention is now focused on the choice of the chromatographic operating mode to minimize eluent consumption and to maximize productivity. Among the alternatives to the traditional batch chromatography, attention is now shifting towards simulated moving bed (SMB) technologies and a review covering the latest developments in this area seems timely. Several aspects of this important analytical technique are presented and details concerning the SMB technology for process optimization are outlined.
\end{abstract}

Keywords: enantiomer separations; chiral stationary phases; liquid chromatography.

\section{INTRODUÇÃ̃o}

A quiralidade de fármacos e medicamentos tem se mostrado um importante assunto do ponto de vista farmacológico, farmacocinético, toxicológico e regulador ${ }^{1}$. O fenômeno da quiralidade não está restrito aos produtos farmacêuticos, sendo igualmente uma característica importante em um número expressivo de agentes biológicos ativos, incluindo inseticidas, herbicidas, sabores e fragrâncias, aditivos alimentícios, etc ${ }^{2}$.

A quiralidade representa uma propriedade intrínseca dos chamados "blocos estruturais da vida", tais como aminoácidos e açúcares e, conseqüentemente, dos peptídeos, proteínas e polissacarídeos. Como resultado dessa natureza quiral vários sistemas biológicos, enzimas e receptores de membrana são sensíveis à estereoquímica de seus substratos e ligantes, realizando um reconhecimento seletivo dos isômeros configuracionais e interagindo diferentemente com cada um dos enantiômeros, ocasionando via de regra diferentes respostas fisiológicas ${ }^{3}$. Como um exemplo clássico e trágico da importância da quiralidade na indústria farmacêutica podemos citar o caso da talidomida. Na década de 60 a talidomida foi comercializada na sua forma racêmica como um sedativo, para aliviar náuseas matinais em gestantes. A talidomida foi posteriormente retirada do mercado por causar sérios efeitos colaterais levando a deformações congênitas em fetos, quando administrado em gestantes ${ }^{4}$. O caso da talidomida foi um marco trágico para a indústria farmacêutica, acarretando mudanças profundas na legislação e no controle de fármacos e medicamentos. Em decorrência de acentuadas diferenças na atividade farmacológica apresentadas pelos enantiômeros de um determinado fármaco, enantiômeros individuais precisam ter suas propriedades farmacológicas (qualitativa e quantitativamente), farmacocinéticas (absorção, distribuição, biotransformação e excreção) e efeitos toxicológicos bem estabelecidos antes de sua comercialização ${ }^{5}$.

*e-mail: roque@iqm.unicamp.br
Devido às diferentes propriedades biológicas que cada enantiômero pode exercer nos processos bioquímicos, a obtenção de substâncias enantioenriquecidas ou enantiopuras tornou-se um grande desafio para os pesquisadores e para a indústria farmacêutica. A experiência acumulada ao longo dos anos levou diversos órgãos regulamentadores internacionais a introduzir legislações mais rígidas no controle clínico dos medicamentos e a exigir da indústria farmacêutica a comercialização de medicamentos na sua forma quiral, não racêmica. As autoridades reguladoras da saúde nos Estados Unidos, o FDA ("Food and Drug Administration"), têm colocado exigências mais rigorosas quanto à concessão de novas patentes de drogas racêmicas, exigindo documentação completa quanto ao perfil farmacológico e farmacocinético dos enantiômeros individuais e de suas combinações. Dentro deste contexto, uma série de vantagens da comercialização de enantiômeros puros sobre a comercialização do racêmico é apresentada na Tabela 1, conforme citado por Ching-Joe ${ }^{6}$.

Durante a última década elevaram-se as expectativas na obtenção de substâncias enantiomericamente puras ou enriquecidas tanto por razões científicas, como econômicas, sendo a indústria farmacêutica o seu principal contribuinte ${ }^{3}$. Entre 1992 e 2000, o mercado mundial para compostos quirais, não racêmicos, aumentou de US\$ 30 bilhões para uma estimativa de US\$ 100 bilhões, com quase duas dúzias de companhias se especializando em separações quirais $^{7}$. Em 2002, a venda mundial de medicamentos como um único enantiômero ultrapassou os US\$ 159 bilhões, sendo que os dois medicamentos mais vendidos nesse mesmo ano, o Liptor e Zocor renderam juntos US\$ 14 bilhões ${ }^{8}$. Rekoske ${ }^{7}$ relatou que entre os 500 fármacos mais vendidas no mundo, 269 já estavam sendo comercializados como um único enantiômero.

As principais metodologias para a obtenção de um único enantiômero de um determinado composto seguem basicamente duas abordagens, como apresentado na Figura 1. A primeira delas apresenta um enfoque quiral e consiste na síntese enantiosseletiva. Nesta metodologia empregam-se moléculas auxiliares ou catali- 
Tabela 1. Possíveis benefícios do uso de enantiômeros puros nas aplicações farmacêuticas

Fármaco quiral racêmico
Apenas um dos enantiômeros pode ser ativo
Um dos enantiômeros pode ser tóxico
Enantiômeros podem apresentar diferentes propriedades
farmacocinéticas
Enantiômeros podem ser metabolizados a diferentes taxas
em uma mesma pessoa
Um dos enantiômeros pode ser metabolizado a diferentes
taxas na população
Um dos enantiômeros pode apresentar tendência de
intromissão em rotas de desintoxicação
Um enantiômero pode ser agonista, o outro antagonista
Enantiômeros variam no espectro de ação farmacológica
e especificidade de tecido

Possíveis vantagens do fármaco enantiomericamente puro

Redução da dose e da carga no metabolismo

Restrições menos rígidas na dosagem, ampliação do uso da droga

Melhor controle da cinética da dosagem

Redução da variabilidade da resposta dos pacientes

Redução da variabilidade da resposta dos pacientes

Maior confiança na padronização da dosagem

Redução nas interações com outros fármacos de uso comum

Aumento da atividade e redução na dosagem

Aumento de especificidade e redução de efeitos colaterais sadores quirais para induzir seletividade na formação de novos centros estereogênicos. Esta estereosseletividade pode ser resultado de indução assimétrica (catalisadores quirais ou a presença de subunidades estruturais assimétricas), ou através de reações em meios biológicos utilizando-se microorganismos, ou ainda na presença de enzimas isoladas. Via de regra, nestes casos, se ambos os enantiômeros forem de interesse, será necessário desenvolver duas sínteses independentes. A segunda abordagem corresponde ao caso inverso, envolvendo uma síntese racêmica gerando ambos os enantiômeros em quantidades equimolares. Nesta abordagem ambos os enantiômeros são posteriormente resolvidos aos respectivos enantiômeros através de metodologia complementar. Esta metodologia geralmente apresenta uma complexidade menor, além de um custo de produção geralmente inferior. Nesta abordagem os enantiômeros podem ser resolvidos por vários métodos: preparação de diastereoisômeros e separação dos mesmos, por cromatografia ou cristalização, ou separação direta dos enantiômeros por membrana ou por cromatografia quiral ${ }^{9}$.

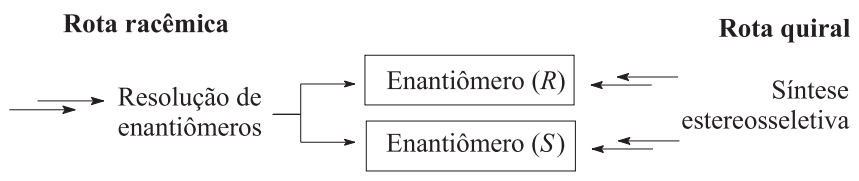

Figura 1. Obtenção de enantiômeros puros ou enriquecidos

O método de resolução de racematos por cromatografia quiral é capaz de fornecer ambos os enantiômeros com alta pureza ótica, e no caso de fármacos em desenvolvimento, possibilita a realização de testes farmacológicos com cada um dos enantiômeros separadamente. No caso de fármacos quirais, durante a "Fase 1" dos testes clínicos, quantidades de 100 a $1000 \mathrm{~g}$ dos dois enantiômeros necessitam ser preparadas para testes farmacológicos e toxicológicos. Desse modo, a pureza enantiomérica e a produção em quantidades adequadas são uma plataforma-chave a ser atingida no desenvolvimento do processo, especialmente quando se tem como meta os estágios subseqüentes denominados de "Fase 2" e "Fase 3", quando os testes clínicos e a produção para o mercado implicam na decisão entre o uso de uma mistura racêmica ou de um enantiômero ${ }^{4}$.

Os métodos de separação quiral usando técnicas de cromatografia líquida têm se mostrado muito eficientes na separação de enantiômeros e podem ser divididos em duas categorias: uma é o método indireto, a qual é baseado na formação de um diastereoisô- mero pela reação do racemato com um reagente quiral. A outra é o método direto, o qual é baseado na formação de um diastereoisômero transiente em uma fase estacionária quiral (FEQ) ou fase móvel quiral ${ }^{10}$. O método indireto de separação quiral envolve a síntese de diastereoisômeros por um agente quiral seguido por cromatografia em uma coluna aquiral. $\mathrm{O}$ método direto envolve separação de substâncias racêmicas em seus correspondentes enantiômeros usando uma FEQ².

As principais vantagens da separação de enantiômeros empregando FEQ são: aplicação a uma larga variedade de compostos racêmicos; possibilidade de obtenção de ambos os enantiômeros; elevados graus de pureza ótica dos enantiômeros isolados; facilidade de operacionalização e a possibilidade de separação de enantiômeros de misturas racêmicas com características especiais, tais como compostos de difícil derivação (hidrocarbonetos, por ex.), facilmente racemizáveis, ou que tenham um tipo incomum de quiralidade (quiralidade do tipo helicoidal, por ex.) ${ }^{11}$.

Cromatografia preparativa em fase estacionária quiral é hoje considerada a técnica mais geral e eficiente para a obtenção de enantiômeros com elevado grau de pureza ótica e tem sido uma ferramenta importante na pesquisa farmacêutica e nas fases iniciais do desenvolvimento de novas drogas ${ }^{9,12}$.

Separações cromatográficas são tradicionalmente realizadas de modo descontínuo (batelada), isto é, uma quantidade de uma mistura é injetada periodicamente sob um fluxo de solvente, o qual escoa através da fase estacionária. A separação é baseada na diferença de afinidade dos componentes a serem separados com a fase estacionária. Para a produção de compostos em larga escala a cromatografia convencional em batelada pode se tornar inviável em termos econômicos, pois se faz necessário o emprego de uma grande quantidade da FEQs, um alto consumo de solvente (fase móvel), altas condições de diluição do produto final e dificuldades associadas ao reciclo, operações descontínuas e utilização de adsorventes não-seletivos ${ }^{13-16}$. Estas desvantagens são sérios obstáculos ao escalonamento do processo. Entretanto, uma parcela significativa dessas dificuldades tem sido superada graças a recentes melhorias nas técnicas cromatográficas e ao desenvolvimento de novas FEQs, relativamente baratas, para propósitos preparativos ${ }^{11}$.

No intuito de superar as desvantagens apresentadas pela cromatografia em batelada, surgiram os métodos cromatográficos contínuos contracorrente. Os processos cromatográficos contínuos originaram-se em 1947 com o desenvolvimento do primeiro processo de adsorção em contracorrente conhecido como processo Hypersorption, desenvolvido pela Union Oil Co., para a purificação de hidrocarbonetos. Em 1961, Broughton e Gerhold idealiza- 
ram o sistema conhecido como Leito Móvel Simulado ("Simulated Moving Bed - SMB"). A partir dos anos 70, a tecnologia foi aplicada pela Universal Oil Products (UOP) com o nome genérico de SORBEX. Este processo foi destinado primeiramente à separação e recuperação de compostos petroquímicos e recuperação de frutose de misturas de glicose e frutose ${ }^{17}$. A partir de então esta tecnologia tem sido amplamente utilizada nas indústrias petroquímicas, de processamento de açúcares e de química fina.

Uma unidade do tipo leito móvel simulado (LMS) consiste em um conjunto de colunas interconectadas em série; o fluxo contracorrente das fases sólida e liquida é simulado por uma troca periódica das correntes de entrada e de saída na direção do fluxo da fase líquida ${ }^{18}$. O contato contracorrente entre a fase sólida e a fase líquida utilizada na cromatografia LMS maximiza os efeitos de transferência de massa entre as fases, resultando em uma elevada produtividade, um menor consumo de solvente e adsorvente quando comparado com sistemas cromatográficos convencionais ${ }^{19,20}$.

O LMS tem sido utilizado em escala industrial desde os anos 60, principalmente nas indústrias petroquímicas, de processamento de açúcares e de química fina. Atualmente, as indústrias biotecnológicas e farmacêuticas têm mostrado um interesse crescente pelos sistemas cromatográficos contínuos. Exemplos de estudos recentes incluem a separação de enantiômeros ${ }^{21-26}$, processamento de açúcares ${ }^{27,28}$, purificação de aminoácidos e proteínas ${ }^{29-34}$ e ácidos orgânicos ${ }^{35}$.

\section{FASES ESTACIONÁRIAS QUIRAIS}

A chave para o sucesso na resolução de racematos deve-se em grande parte às FEQs utilizadas. A viabilidade econômica do processo LMS é ditada pelas propriedades fundamentais da FEQ no que diz respeito a sua seletividade, capacidade de saturação e eficiência, parâmetros que controlam a dimensão da unidade e a produtividade específica realizável do processo por unidade de massa da FEQ. Outros parâmetros importantes da FEQ referem-se a: estabilidade química, a qual limita o número de fases móveis disponíveis e, indiretamente, a solubilidade máxima do soluto; estabilidade mecânica, a qual é particularmente importante em aplicações de CLAE (cromatografia líquida de alta eficiência), onde pequenas partículas são utilizadas e elevadas quedas de pressão são impostas; tempo de vida médio. Todos estes parâmetros devem ser levados em consideração ao selecionar-se uma FEQ específica para separações no $\mathrm{LMS}^{4}$.

Uma perspectiva histórica da resolução de racematos através da cromatografia é apresentada na Tabela $2^{36}$. A primeira resolução direta de enantiômeros através de cromatografia gasosa foi relatada em 1966, e a resolução de enantiômeros através de cromatografia líquida foi alcançada inicialmente por troca iônica, em 1971. Desde a década de 70, um número considerável de pesquisas tem sido realizado enfocando o desenvolvimento de fases estacionárias quirais e de seletores quirais capazes de exibir enantiosseletividade para uma larga faixa de compostos quirais. Atualmente as principais classes de FEQs comercialmente disponíveis são baseadas em um número variado de seletores quirais incluindo-se proteínas, polissacarídeos, ciclodextrinas, fases do tipo Pirkle, resinas de troca iônica, éteres de coroa, antibióticos macrocíclicos, e polímeros quirais ${ }^{52}$.

A maioria das separações em LMS tem sido executadas em FEQs baseadas em polissacarídeos, tais como celulose e amilose ${ }^{4}$ (Figura 2). As moléculas da celulose contem ligações $\beta$-glicosídicas do tipo $\beta(1 \rightarrow 4)$ e formam uma estrutura linear, enquanto que as moléculas da amilose apresentam ligações $\alpha$-glicosídicas do tipo $\alpha(1 \rightarrow 4)$ e adotam uma estrutura helicoidal ${ }^{52}$. Estes polissacaríedos demonstram reconhecimento quiral, mas não são FEQs de utilidade prática, pois tendem a ter baixas propriedades mecânicas e cromatográficas, apesar de seu baixo custo, ampla disponibilidade e
Tabela 2. Apanhado histórico de separações quirais por cromatografia, adaptada da ref. 36

1939 Handerson e Rule: Resolução de derivados de cânfora racêmica ${ }^{37}$

1952 Dalgliesh: Regra dos três pontos em cromatografia de papel para aminoácidos ${ }^{38}$

1966 Gil-Av et al.: Resolução direta de enantiômeros por cromatografia gasosa ${ }^{39}$

1971 Davankov e Rogozhin: Cromatografia quiral de troca iônica ${ }^{40}$

1972 Wulff e Sarhan: Polímeros análogos de enzimas para cromatografia líquida quiral $^{41}$

1973 Hesse e Hagel: Triacetato de celulose utilizado para resolução quiral ${ }^{42}$

1973 Stewart e Doherty: Agarose ligada à albumina de soro bovino (ASB) para resolução quiral ${ }^{43}$

1974 Blaschke: Síntese de polímeros quirais ${ }^{44}$

1975 Cram et al.: Cromatografia com éteres de coroa quiral ${ }^{45}$

1979 Pirkle e House: Síntese da primeira fase estacionária quiral ligada à sílica ${ }^{46}$

1979 Okamoto et al.: Síntese de polímeros helicoidais para cromatografia líquida quiral ${ }^{47}$

1982 Allenmark: Utilização de agarose ligada à ASB em cromatografia líquida quiral $^{48}$

1983 Hermansson: Utilização da sílica ligada a $\alpha_{1}$-ácido glicoproteína para resolução quiral ${ }^{49}$

1984 Armstrong e DeMond: Utilização de ciclodextrinas ligadas à sílica ${ }^{50}$

1995 Armstrong, Liu e Ekbork-Ott; Fases estacionárias baseadas em antibióticos ${ }^{51}$

não necessitarem de longo tempo de preparação $0^{53}$. A derivação desses polímeros fornece FEQs com elevado reconhecimento quiral, que podem separar uma grande classe de compostos racêmicos em seus respectivos enantiômeros ${ }^{54}$.

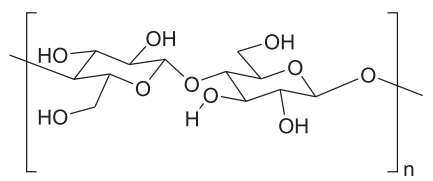

celulose

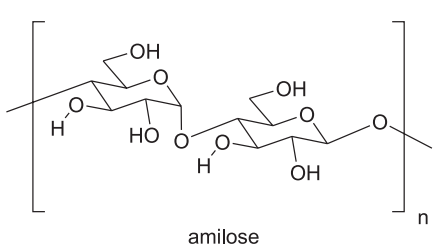

Figura 2. Estrutura química da celulose e amilose

O primeiro derivado de celulose utilizado para separações em uma escala preparativa foi o triacetato de celulose microcristalina (MCTA), produto da acetilação heterogênea da celulose microcristalina $^{11}$ (Figura 3). O reconhecimento quiral pelo MCTA devese a sua acetilação heterogênea com subseqüente expansão desta por aquecimento em álcool, de forma que a estrutura original do polímero é preservada ${ }^{20}$. Embora a habilidade do MCTA para reconhecimento quiral tenha sido relatada por diversos autores, o mecanismo de reconhecimento quiral ainda permanece obscuro. Hesse e Hagel $^{42}$ propuseram o conceito de complexo de inclusão cromatográfica: interações dos compostos quirais ocorrendo por inclusão em cavidades assimétricas do polissacarídeo. A força da interação é determinada pelo ajuste das espécies quirais às cavida- 
des quirais do MCTA expandido. Pais et al. ${ }^{19}$ afirmaram que, contrariamente às fases estacionárias comuns, a adsorção em MCTA parece ser fortemente influenciada por interações estéricas entre as espécies quirais e os substituintes da fase estacionária.

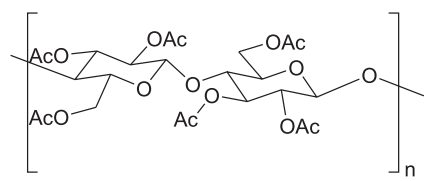

Figura 3. Estrutura química do MCTA

O MCTA é uma fase estacionária relativamente barata quando comparada a outras FEQs, possuindo boa estabilidade mecânica e alta capacidade de saturação, podendo resolver misturas racêmicas com boa seletividade. Entretanto, a eficiência desta fase estacionária é baixa ${ }^{11,55-58}$ e não se apresenta estável em muitos solventes ${ }^{58}$. Metanol, etanol, 2-propanol e misturas destes álcoois com água ou hidrocarbonetos são as fases móveis mais utilizadas ${ }^{58}$.

A Tabela 3 apresenta trabalhos recentes utilizando o MCTA em unidades LMS e os respectivos enantiômeros separados.

Tabela 3. Exemplos recentes de trabalhos utilizando MCTA como FEQ

\begin{tabular}{lll}
\hline Racemato & Fase móvel & Ref. \\
\hline Cetamina & Etanol & 21 \\
Base de Tröger & Etanol & 45 \\
Epóxido quiral & Metanol & 19 \\
\hline
\end{tabular}

As FEQs baseadas em celulose e amilose mais utilizadas são preparadas pelo recobrimento destes polissacarídeos derivatizados (na forma de benzoatos ou carbamatos) em uma matriz de sílica gel pré-tratada e podem ser utilizadas tanto no modo normal, quanto no modo reverso de eluição ou, ainda, polar orgânico ${ }^{59}$. Os principais sítios de adsorção nos derivados de benzoatos são os grupos polares carboxilatos os quais interagem com os racematos através de ligações de hidrogênio e de interações dipolo-dipolo. Nos derivados de carbamatos, os solutos podem interagir com os grupos $\mathrm{C}=\mathrm{O}$ e $\mathrm{NH}$ através de ligações de hidrogênio e com os grupos $\mathrm{C}=\mathrm{O}$ através de interações dipolo-dipolo. $\mathrm{O}$ reconhecimento quiral e a habilidade de resolução destes grupos dependem da estrutura tridimensional do polissacarídeo funcionalizado, e também dos substituintes introduzidos nos grupos fenilas ${ }^{60}$. Em cada unidade de glicose dos biopolímeros celulose ou amilose, existem cinco centros estereogênicos disponíveis para associações diastereoisoméricas com um analito quiral. Desta forma, FEQs baseadas nestes dois polissacarídeos possuem uma elevada capacidade de saturação, sendo ideais para propósitos preparativos. A principal desvantagem deste tipo de FEQ é o número limitado de solventes que podem ser empregados. Fases móveis não-polares, compostas por hexano, heptano, metanol, ou 2-propanol (até 10\%), são as mais comumente recomendadas ${ }^{61}$.

Algumas destas FEQs estão disponíveis comercialmente, sendo que as mais utilizadas para fins preparativos são (Figura 4): Chiralcel OD (tris-(3,5-dimetilfenilcarbamato) de celulose), Chiralcel OJ (tris-(4-metilbenzoato) de celulose), Chiralcel OB (tribenzoato de celulose) Chiralpak AD (tris-(3,5-dimetilfenilcarbamato) de amilose), Chiralpak AS (tris-(1-(S)-feniletilcarbamato de amilose). Assim como em cromatografia analítica quiral, as Chiracel OD e Chiralpak AD têm sido as FEQs mais utilizadas em cromatografia quiral preparativa. A capacidade de saturação destas FEQs é reconhecida como um importante recurso na obtenção de elevados valores de produtividade variando desde $10 \mathrm{~g}$ até $1.500 \mathrm{~g}$ de racemato por $\mathrm{kg}$ de FEQ por dia ${ }^{9,16}$.
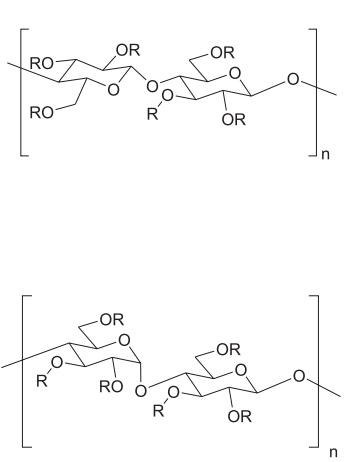

$\mathrm{R}$

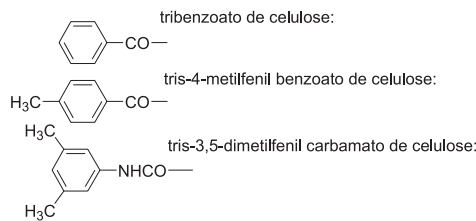

Figura 4. Estrutura química das FEQs comercialmente disponíveis, mais utilizadas, baseadas em celulose e amilose para separações preparativas

Duas FEQs baseadas em dialiltartadiamida (DATD) (Figura 5), $N, N^{\prime}$-dialil-L-tartadiamida bis-(4-tert-butilbenzoato) (DATD-TBB) e $N, N^{\prime}$-dialil-L-tartadiamida bis-(3,5-dimetilbenzoato) (DATDDMB), covalentemente ligada à sílica Kromasil contendo ligações cruzadas, têm sido utilizadas para separar enantiômeros tanto em escala analítica como em escala preparativa ${ }^{62,63}$. Nestas FEQs a retenção e a seletividade são oriundas principalmente de múltiplas ligações de hidrogênio, além de interações estéricas e $\pi$ - $\pi$ que também são consideradas presentes. Devido às propriedades das ligações de hidrogênio, as separações utilizando este tipo de FEQ são normalmente realizadas em solventes não-polares, dado que um solvente polar irá diminuir as interações entre o analito e o seletor quiral, devido a uma solvatação não-favorável do analito na fase móvel. Seletores baseados em DATD com substituintes alifáticos nos grupos hidroxilas demonstraram menor seletividade que os seletores com um substituinte aril ${ }^{64}$. A investigação do efeito dos substituintes nos grupos arila mostrou que eles influenciam significantemente a seletividade, especialmente quando a posição para é modificada $^{62}$. Acredita-se que o seletor DMB possui maior seletividade para racematos em geral, porém o seletor TBB apresenta maior seletividade para racematos ácidos ${ }^{64}$.

Andersson et al. $^{52}$ e Francotte $^{9}$ apresentaram uma classificação
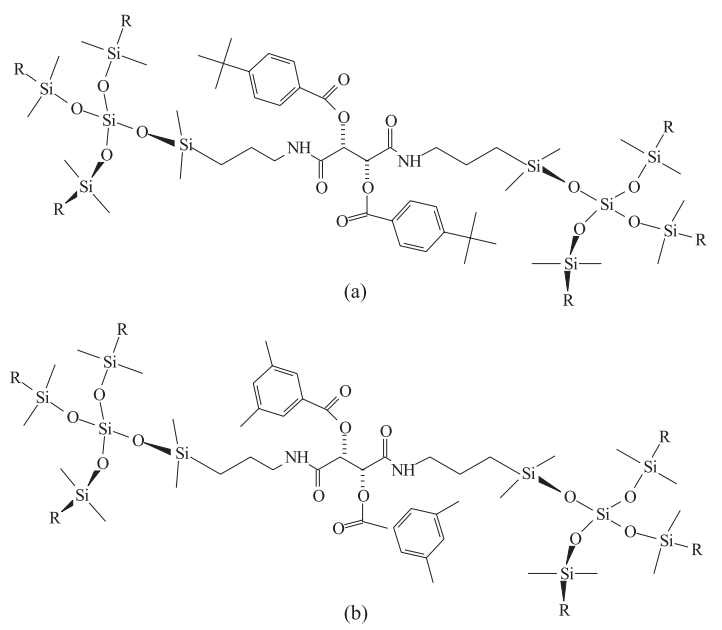

Figura 5. Estrutura química dos seletores quirais da DATD: (a) DATD-TBB; (b) $D A T D-D M B$ 
para as FEQs freqüentemente utilizadas em cromatografia preparativa com relação a sua capacidade de saturação. FEQs baseadas em polissacarídeos possuem maior capacidade, seguida das FEQs baseadas nas poliacrilamidas, dialiltartadiamidas e do tipo "Brush" possuindo capacidades aproximadamente idênticas - e, por fim, as FEQs baseadas em proteínas.

A escolha da fase móvel é outro ponto crítico para separações de enantiômeros de cunho preparativo, a qual exerce influência direta na eficiência do processo cromatográfico. Parâmetros importantes, tais como seletividade da separação, tempo de retenção e solubilidade do racemato, apresentam alta sensibilidade com relação às mudanças de composição da fase móvel. Outros parâmetros, como por ex., a resolução, também podem ser afetados pela fase móvel. Este é o caso em especial das fases estacionárias baseadas em polissacarídeos. Em alguns casos, o impacto da fase móvel é tão forte que mudanças na composição da fase móvel causam uma inversão da ordem de eluição dos enantiômeros. Por esta razão, antes de executar uma separação preparativa é recomendado estabelecer a ordem de eluição de ambos os enantiômeros em escala analítica, sob as mesmas condições experimentais para a separação preparativa. Isto pode ser feito por detecção polarimétrica ou por injeção de enantiômeros individuais. No entanto, este estudo deve ser interpretado cuidadosamente porque para alguns compostos quirais, o sinal da rotação óptica pode ser invertido com a mudança do solvente'.

Devido a um grande número de FEQs baseadas em polissacarídeos possuírem maior ou menor solubilidade em solventes orgânicos, uma série de FEQs têm sido imobilizadas através de um tratamento fotoquímico ou térmico das fases baseadas em polissacarídeos (Figura 6). Pela simples aplicação de uma destas duas técnicas, a imobilização ocorrerá presumivelmente pela formação de ligações cruzadas das cadeias do polissacarídeo. Dependendo do tipo de processo térmico ou fotoquímico empregado, uma das FEQs poderá ser mais eficiente que a outra ${ }^{9,65}$.

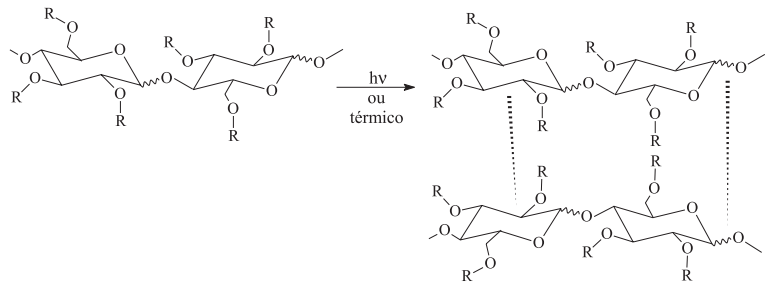

Figura 6. Processo de imobilização de FEQs baseado em polissacarídeos. Adaptado da ref. 65

\section{PRINCÍPIOS BÁSICOS DOS LEITOS MÓVEIS - DIFERENCIAÇÃO ENTRE LEITO MÓVEL VERDADEIRO E LEITO MÓVEL SIMULADO}

A idéia básica de um sistema com leito móvel é promover um contato contracorrente entre as fases sólidas e líquidas. As grandes vantagens do contato contracorrente entre as fases estacionária (fase sólida) e a móvel (fase líquida) são a alta produtividade, o baixo consumo de solvente e um aumento na performance de separação, gerando uma elevada recuperação do produto com elevado grau de pureza, mesmo quando a seletividade é próxima da unidade ou a eficiência da fase estacionária é baixa ${ }^{59}$. Entretanto, o movimento real contracorrente entre as fases sólidas e líquidas não é um processo eficiente, devido à dificuldade causada pelo movimento da fase sólida.

No leito móvel verdadeiro (LMV) as fases sólida e líquida escoam em direções opostas (sentido contracorrente). Sendo as afinidades de $A$ e $B$ para com a fase sólida diferentes $(A<B)$, é possível escolher vazões para fazer $A$ movimentar-se para cima e $B$ movimentar-se para baixo, conduzindo a uma separação espacial, como apresentado na Figura 7. Este sistema requer duas linhas de entrada (uma para a alimentação e outra para o dessorvente) e duas linhas de retirada (uma para o refinado $A$ e outra para o extrato $B)^{66}$.
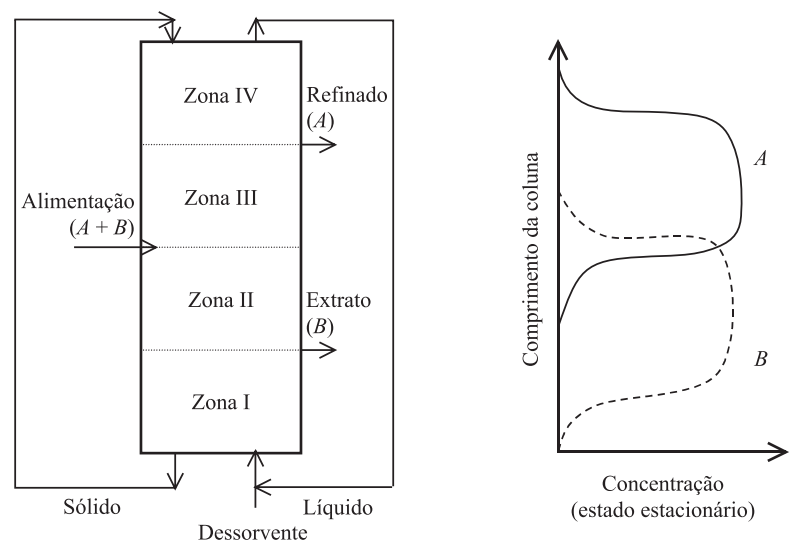

Figura 7. Princípio básico do LMV e um típico perfil de concentrações (à direita). O componente B é adsorvido mais fortemente que o componente A

O LMV clássico (Figura 7) possui quatro zonas diferentes. O líquido saindo na zona IV é reciclado na zona I, enquanto que o sólido saindo na zona I é reciclado na zona IV. Em ambos os caminhos, a zona I é localizada entre a entrada de dessorvente e saída de extrato, a zona II está entre as saídas de extrato e refinado, a zona III separa a alimentação e retirada de refinado e a zona IV está localizada entre as retiradas de refinado e extrato ${ }^{67}$.

Cada zona do LMV possui um papel específico na separação ${ }^{68,69}$ : zona I (entre a entrada de dessorvente e a saída de extrato) - o produto mais retido $(B)$ deve ser completamente dessorvido; zona II (entre o ponto de alimentação e saída de extrato) - o produto menos retido $(A)$ deve ser completamente dessorvido; zona III (entre o ponto de alimentação e saída do refinado) - o produto mais retido $(B)$ deve ser completamente adsorvido e, zona IV (entre a saída de refinado e entrada de dessorvente) - o produto menos retido $(A)$ deve ser completamente adsorvido.

A cromatografia em leito móvel simulado é um processo de separação contínuo que possui importantes aplicações industriais e consiste em uma unidade formada por um circuito de colunas cromatográficas empacotadas com um adsorvente apropriado que é dividido em quatro zonas, podendo conter duas ou mais colunas por zonas. Na tecnologia do leito móvel simulado (LMS) válvulas rotatórias ou de multiposições são utilizadas para periodicamente mudar a posição das linhas de alimentação, de extrato, e de refinado, ao longo do leito, no sentido do fluxo da fase líquida ${ }^{69,70}$. Essas trocas são efetuadas em intervalos regulares, promovendo um movimento relativo contracorrente resultando no conceito do LMS. O uso de válvulas rotatórias especiais controladas por computador permite fazer as trocas das correntes de forma simultânea e eficiente ${ }^{71}$.

Existem duas possíveis configurações para a unidade LMS: circuito aberto e circuito fechado (Figura 8). A diferença básica entre estas duas configurações é que no circuito aberto não há reciclo do eluente (dessorvente), portanto existem duas correntes de entrada (corrente de entrada da alimentação e dessorvente) e três correntes de saída (correntes de saída de extrato, de refinado e de dessorvente). Para o circuito de malha fechada há reciclo de eluente e, portanto, duas correntes de entrada (correntes de entrada alimentação e dessorvente) e duas correntes de saída (correntes de saída de extrato e de refinado). 
(a)

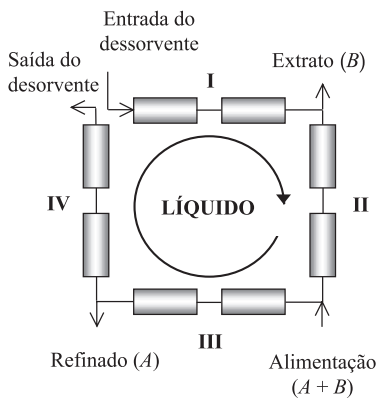

(b)

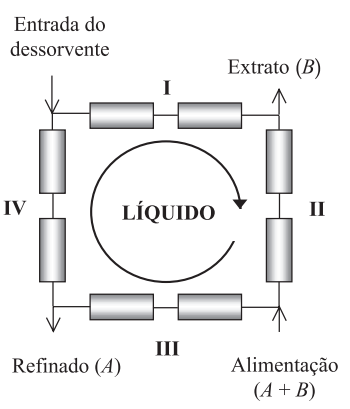

Figura 8. Possíveis configurações de uma unidade LMS com quatro zonas (duas colunas por zona): (a) circuito aberto; (b) circuito fechado

Em ambas configurações, o soluto $(A)$ com menor afinidade pelo adsorvente é removido na corrente de saída do refinado, enquanto o soluto $(B)$ com maior afinidade pelo adsorvente é removido na corrente de extrato. Assim como na cromatografia em batelada, o soluto $A$ migra mais rápido que o soluto $B$ na direção do fluxo da fase líquida. Em um sistema de LMS com quatro zonas, o soluto $A$ é adsorvido na zona IV e dessorvido na zona II. A adsorção do componente $B$ ocorre na zona III, e a sua dessorção ocorre na zona I.

O LMS possui diferentes correntes líquidas que estão interligadas. É de fundamental importância o conhecimento do balanço de massa para cada componente em cada um dos nós de ligação do LMS. Todas as vazões internas estão relacionadas com as vazões de entrada e de saída nas unidades por meio de balanço de massa em cada nó (Figura 8), nas quais $Q_{\mathrm{I}}, Q_{\mathrm{II}}, Q_{\mathrm{III}}$ e $Q_{\mathrm{IV}}$ são as vazões volumétricas nas correspondentes zonas do LMS, $Q_{\mathrm{F}}$ é a vazão de alimentação, $Q_{\mathrm{D}}$ é a vazão de dessorvente, $Q_{\mathrm{E}}$ é a vazão do extrato e $Q_{\mathrm{R}}$ é a vazão de refinado. Entretanto, devido à diferença entre as duas configurações citadas deve-se ter maior atenção ao realizar estes balanços. Uma descrição detalhada dos balanços de massa em unidades LMS pode ser encontrada em Nicoud ${ }^{68}$.

A principal diferença entre o LMV e o LMS é com relação ao regime estacionário: o LMV é projetado para operar sob estado estacionário e o LMS sob estado estacionário cíclico, caracterizado por perfis de concentração transientes idênticos em cada período entre as trocas de posições de duas válvulas. O estado estacionário cíclico é normalmente alcançado após um certo número de ciclos, mas o estado do sistema ainda permanece variando com o tempo, devido ao movimento periódico das linhas de entrada e de saída ao longo das colunas. Aumentando o número de colunas no LMS e diminuindo os seus comprimentos, o LMS se aproximará do LMV. Portanto, é esperado que o comportamento de unidade LMS seja satisfatoriamente previsto considerando-a como uma unidade LMV equivalente no caso da unidade LMS com número suficientemente elevado de colunas ${ }^{24}$.

\section{CONDIÇÕES DE OPERAÇÃO E PARÂMETROS DE DESEMPENHO DE UMA UNIDADE LMS}

O projeto de uma unidade LMS requer a escolha de condições operacionais (tempo de troca e vazões em cada seção da unidade). Considerando a complexidade dinâmica de operação do LMS, a escolha de condições operacionais não é uma tarefa simples ${ }^{18}$. Diversos grupos têm dedicado estudos visando a otimização das condições operacionais de unidades LMS e diferentes metodologias para determinação destes parâmetros de projeto têm sido relatadas, dentre as quais podemos destacar o método do triângulo base- ado na teoria do equilíbrio ${ }^{72}$, o método dos volumes de separação ${ }^{73}$ e o conceito das ondas estacionárias ${ }^{74}$.

O método do triângulo é aplicado tanto para sistemas que apresentam isotermas de adsorção lineares, quanto para sistemas descritos por modelos de Langmuir estequiométrico ou não estequiométrico, onde a mistura axial e as resistências à transferência de massa são negligenciadas e o equilíbrio de adsorção é suposto em todos os locais durante todo o tempo na coluna. Nesta metodologia apenas os parâmetros de equilíbrio de adsorção são considerados na determinação da região de completa separação (teoria do triângu$10)^{59}$. A teoria do triângulo, por não levar em conta efeitos de dispersão e de transferência de massa na determinação das condições de operação de uma unidade LMS, não é capaz de predizer a pureza do produto desejada com as vazões nas zonas, com os comprimentos das zonas, e com os parâmetros de transferência de massa. Desta forma, o projeto baseado na teoria do equilíbrio serve como uma suposição inicial para otimização do LMS. A otimização das condições operacionais pode ser obtida pelo uso de um modelo completo, que inclui efeitos de transferência de massa ${ }^{18}$.

No intuito de superar as desvantagens apresentadas pelo método do triângulo, metodologias mais detalhadas foram desenvolvidas. As metodologias das ondas estacionárias e dos volumes de separação são mais robustas que o método do triângulo, por levarem em conta tanto os parâmetros de equilíbrio de adsorção quanto as resistências à transferência de massa e dispersão na determinação das condições de operação na unidade LMS. Foi demonstrada uma significante redução na região de completa separação ao se introduzirem os efeitos de transferência de massa ${ }^{73,74}$.

Apesar das limitações apresentadas pelo modelo do equilíbrio esta metodologia tem sido amplamente aplicada com sucesso para separações de misturas binárias, tanto em condições lineares quanto sob condições não-lineares, das isotermas de equilíbrio de adsorção.

Uma completa descrição das metodologias aplicadas no projeto das condições operacionais pode ser encontrada em Migliorini et al..$^{75}$ e Mazzotti et al. ${ }^{69}$ para a teoria do triângulo, Ma e Wang ${ }^{74}$, Cremasco e Wang ${ }^{31}$, Xie et al. ${ }^{76,77}$ para o método das ondas estacionárias e Azevedo e Rodrigues ${ }^{73}$ e Rodrigues e Pais ${ }^{78}$ para o método dos volumes de separação.

O desempenho do LMS é caracterizado principalmente por quatro parâmetros: pureza, recuperação, consumo de solvente e produtividade. Para o caso da separação de uma mistura binária no LMS, no qual o componente mais retido $(B)$ é recuperado no extrato e o componente menos retido $(A)$ é recuperado no refinado, os quatro parâmetros do processo são definidos na Tabela 4 , onde $C_{A}^{R}$ e $C_{A}^{F}$ são as concentrações de $A$ no refinado e na alimentação, respectivamente; $C_{B}^{E}$ e $C_{B}^{F}$ são as concentrações de $B$ no extrato e na alimentação, respectivamente; e $V_{S}$ é o volume da fase sólida ${ }^{65}$.

Uma unidade LMS geralmente opera sob condições de sobrecarga, provocando melhorias no desempenho de separação mencionadas anteriormente, mas conduzem a um comportamento nãolinear das isotermas de adsorção competitivas. Isto deve ser considerado na seleção das condições operacionais, isto é, concentração de alimentação, tempo de troca e vazões internas da fase fluida ${ }^{79}$. A concentração de alimentação possui uma forte influência no desempenho do LMS e deve ser bem avaliada. A produtividade e o consumo de eluente são os dois principais critérios econômicos envolvidos no processo cromatográfico. A produtividade aumenta e o consumo de eluente diminui quando a concentração de alimentação aumenta; as variações são normalmente bastante íngremes para uma pequena faixa de concentração e bem suaves para o caso oposto. Como conseqüência, baixas concentrações de injeção devem ser evitadas. Porém, concentrações muito altas podem não ser 
Tabela 4. Definição dos parâmetros de desempenho do processo

\begin{tabular}{lcc}
\hline $\begin{array}{l}\text { Parâmetros do } \\
\text { processo }\end{array}$ & Extrato & Refinado \\
\hline Pureza (\%) & $P_{E}=\frac{100 C_{B}^{E}}{C_{A}^{E}+C_{B}^{E}}$ & $P_{R}=\frac{100 C_{A}^{R}}{C_{A}^{R}+C_{B}^{R}}$ \\
Recuperação (\%) & $R_{E}=\frac{100 C_{B}^{E} Q_{E}}{C_{F}^{T} Q_{F}}$ & $R_{E}=\frac{100 C_{A}^{R} Q_{R}}{C_{F}^{T} Q_{F}}$ \\
$\begin{array}{l}\text { Consumo de solvente } \\
\text { (L/kg) }\end{array}$ & $C S_{E}=\frac{Q_{I}+Q_{F}-Q_{I V}}{C_{B}^{E} Q_{E}}$ & $C S_{R}=\frac{Q_{I}+Q_{F}-Q_{I V}}{C_{A}^{E} Q_{R}}$ \\
$\begin{array}{l}\text { Produtividade } \\
\left(\mathrm{g} \times \mathrm{h}^{-1} / \mathrm{kg} \text { de FEQ) }\right.\end{array}$ & $P R_{E}=\frac{Q_{E} C_{B}^{E}}{V_{S}}$ & $P R_{R}=\frac{Q_{R} C_{A}^{R}}{V_{S}}$ \\
\hline
\end{tabular}

Os símbolo referem-se à: $\mathrm{P}$; pureza dos compostos obtidos, $\mathrm{PR}$; produtividade, C; concentrações, Q; vazões volumétricas e V; volume na unidade de cromatografia contínua, com os seguintes subscritos e superscritos: E - extrato; R - rafinado; A - componente A; B - componente B; F - alimentação; S - adsorvente; T - total. I e IV: referem-se à numeração das zonas de entrada e saída da unidade cromatográfica.

satisfatórias, pois podem conduzir a uma baixa vazão de alimentação, o que pode ser de difícil controle ${ }^{80}$.

\section{TECNOLOGIA DO LMS PARA SEPARAÇÕES DE ENANTIÔMEROS}

Em 1992, a primeira enantiosseparação cromatográfica realizada com sucesso aplicando o princípio do LMS foi publicada por Negawa e Shoji ${ }^{81}$. Esta primeira publicação mostrou a superioridade de LMS frente à cromatografia em batelada no que diz respeito ao aumento da produtividade (61:1 LMS:batelada) e redução no consumo de dessorvente (1:87 LMS:batelada).

Além das vantagens apresentadas no trabalho pioneiro de Negawa e Shoji, a tecnologia do LMS é mais robusta que outras técnicas cromatográficas preparativas, pois requer um menor número de pratos teóricos e não necessita de elevados valores de seletividade para alcançar a mesma produtividade ${ }^{4,70,80}$. Isto é devido ao contato contracorrente entre as fases, que potencializa os efeitos de transferência de massa e, também, ao fato de que, contrário à cromatografia preparativa em batelada, na cromatografia preparativa em LMS os dois enantiômeros não serem completamente separados em cada coluna do sistema cromatográfico, mas apenas nos locais onde o extrato e o refinado são retirados ${ }^{82,83}$, conforme apresentado na Figura 9.

Recentemente, Grill et al. ${ }^{22}$ realizaram um estudo comparativo entre três técnicas cromatográficas preparativas para resolução de intermediários farmacêuticos: CLAE em batelada, reciclo em estado estacionário e LMS. Estes autores constataram que a técnica do LMS foi a que apresentou melhores resultados, sendo capaz de
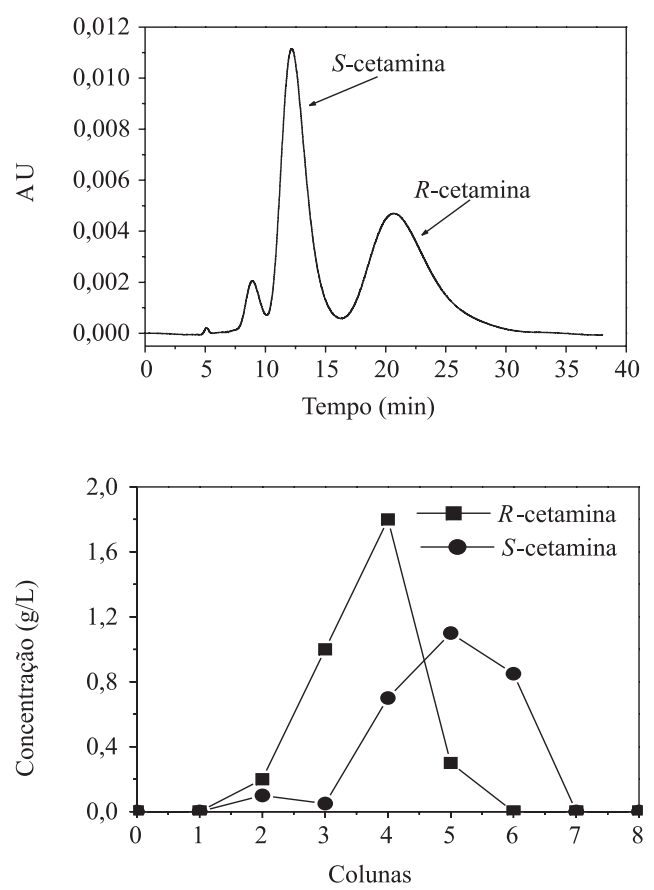

Figura 9. Perfis de concentração na separação dos enantiômeros da cetamina no sistema MCTA e etanol a $25^{\circ} \mathrm{C}$ : (a) perfil de eluição da cetamina em uma coluna de MCTA; (b) perfil interno de concentração da cetamina em uma unidade LMS com oito colunas de MCTA (duas colunas por zona). Adaptados das ref. 83 e 21 , respectivamente

processar $247 \mathrm{~kg}$ de racemato com uma produtividade de $4100 \mathrm{~g}$ de racemato/kg de FEQ por dia, com $98,4 \%$ de excesso enantiomérico e com um consumo de solvente de $0,11 \mathrm{~L} / \mathrm{g}$ de racemato. Já Miller et al. ${ }^{84}$ relataram um estudo comparativo entre CLAE em batelada e LMS para separação de racematos farmacêuticos. Estes autores processaram um total de $1070 \mathrm{~kg}$ de racemato em seis experimentos (um experimento em CLAE e cinco em LMS) onde foi constatado que a tecnologia LMS apresentou as mais altas produtividades e menor consumo de solvente, conforme apresentado na Tabela 5.

A cromatografia preparativa geralmente é realizada a altas concentrações por razões econômicas e, nestas condições, as isotermas de equilíbrio raramente são lineares ${ }^{85,86}$. A operação da unidade LMS sob condições não-lineares é favorável para aplicações preparativas porque possibilita o uso mais eficiente da fase estacionária. Porém, sob estas condições o comportamento de retenção dos enantiômeros depende das suas próprias concentrações na fase estacionária e deve ser descrito através de isotermas de adsorção competitivas ${ }^{4}$ onde, em muitos casos, o equilíbrio dos enantiômeros com a fase estacionária quiral tem sido relacionado com base nos modelos empíricos competitivos de Langmuir, Langmuir modificado e bi-Langmuir ${ }^{87}$. Em cromatografia preparativa, a alimenta-

Tabela 5. Resultados comparativos entre as técnicas cromatográficas em batelada e LMS

\begin{tabular}{lccc}
\hline Técnica & $\begin{array}{c}\text { Quantidade } \\
\text { processada }(\mathrm{kg})\end{array}$ & $\begin{array}{c}\text { Produtividade } \\
\text { (g racemato/kg FEQ por dia) }\end{array}$ & $\begin{array}{c}\text { Consumo de solvente } \\
(\mathrm{L} / \mathrm{g} \text { de racemato) }\end{array}$ \\
\hline Batelada & 77 & 1410 & 0,550 \\
LMS (campanha 1) & 70 & 2050 & 0,174 \\
LMS (campanha 2) & 37 & 2800 & 0,127 \\
LMS (campanha 3) & 297 & 1650 & 0,240 \\
LMS (campanha 4) & 289 & 1670 & 0,260 \\
LMS (campanha 5) & 304 & 1050 & 0,286
\end{tabular}


ção com concentrações mais elevadas é um parâmetro essencial e também decide se um processo de separação pode ser executado economicamente ou não. Em particular, o equilíbrio de adsorção a concentrações mais elevadas (caráter competitivo das isotermas) e restrições relacionadas à solubilidade são parâmetros decisivos na escolha das melhores condições de operação (vazões entre as zonas do LMS e os tempos de troca) para alcançar os desempenhos de separação desejados ${ }^{69,88}$.

Diversos trabalhos têm sido realizados utilizando a teoria do triângulo tanto sob condições lineares quanto sob condições não-lineares das isotermas de adsorção. As Tabelas 6 e 7 apresentam resultados recentes de separações em unidades LMS, sob condições lineares e não-lineares das isotermas de adsorção, respectivamente.

Normalmente, elevando-se as exigências de pureza enantiomérica em experimentos no LMS há uma queda significativa de produtividade. A extensão desta queda depende fortemente dos parâmetros termodinâmicos e cinéticos da separação sob investigação. Em função disso, o processo de recristalização tem sido utilizado com uma técnica auxiliar para o enriquecimento enantiomérico ${ }^{95-97}$.

Desenvolvimentos recentes no campo do LMS têm destacado a possibilidade de se melhorar o desempenho de separação aplicando-se modos de operação não convencionais. Estes modos incluem LMS com fluido supercrítico ${ }^{98,99}$, LMS com gradiente de temperatura ${ }^{100}$, LMS com gradiente de solvente ${ }^{23,89,101}$ e LMS com configuração multifracionada ${ }^{102,103}$, os quais operam com vazões constantes durante cada troca de período (troca das posições de entrada e de saída na unidade) $)^{104}$

Em contraste aos conceitos clássicos no qual o processo do LMS é operado com vazões de entrada, de saída e de alimentação constantes, recentemente a operação do processo LMS foi melhorada por variações de parâmetros operacionais durante os intervalos de troca. O primeiro processo desenvolvido nesta rota foi a unidade denominada VariCol, onde as correntes de entrada e de saída são trocadas assincronicamente ${ }^{13}$. Isto significa que a unidade não mais é completamente equivalente ao LMV, mas que agora tem mais parâmetros a serem aperfeiçoados, ou seja, os tempos de troca dos fluxos de entrada e de saída ${ }^{105-108}$.

Ludemann-Houmbourger et al. ${ }^{106}$ concluíram através de estudos teóricos e experimentais que a produtividade e consumo de eluente são mais favoráveis para o processo VariCol. Estudos com- parativos entre os processos LMS e VariCol demonstram que a melhoria na produtividade pode ser alcançada com um menor número de colunas ${ }^{105-107}$.

Recentemente, Zang e Wankat ${ }^{104}$ propuseram a possibilidade das vazões da fase fluida variarem com o tempo durante o período de troca das posições de entrada e saída na unidade cromatográfica. Este processo refere-se a uma variante do processo LMS conhecida como operação "PowerFeed". Para processos com trocas assíncronas, complicados algoritmos de controle para as válvulas são necessários. Zhang et al. ${ }^{109}$ demonstraram que os processos PowerFeed e VariCol sempre promovem melhores desempenhos com relação ao processo LMS, e que a extensão desta melhoria é maior para separações mais difíceis. Isto é devido ao aumento da complexidade destes dois modos de operação, o qual em essência permite a mudança das vazões dentro da unidade durante o período de troca, para melhorar o desempenho de separação.

Para superar as desvantagens apresentadas devido às dificuldades no controle destas operações, um novo modo de operação foi relatado por Schramm et al. ${ }^{13}$, onde a concentração de alimentação é variada dentro de cada ciclo de troca. Este processo foi denominado ModiCon (modificação periódica da concentração de alimentação). Estes autores concluíram que a produtividade e a concentração do produto podem ser aumentadas enquanto simultaneamente o consumo de solvente pode ser diminuído quando comparados com processos convencionais, os quais operam com concentração de alimentação constante.

Zhang e colaboradores ${ }^{110}$ publicaram um trabalho comparativo entre os processos LMS e as suas variantes, os processos VariCol, PowerFeed e ModiCon. O desempenho de separação foi investigado numericamente e os resultados apresentados por estes autores demonstram que uma melhoria no desempenho de separação pode ser alcançada utilizando estas operações não convencionais com um menor número de colunas.

\section{A TECNOLOGIA DO LMS PARA PRODUÇÃO DE ENANTIÔMEROS EM LARGA ESCALA}

A utilização da tecnologia do LMS pelas indústrias farmacêuticas para obtenção em larga escala de enantiômeros a partir de compostos racêmicos teve início somente após 1990, quando cientistas da UOP e da firma francesa de separação Novasep iniciaram

Tabela 6. Exemplos recentes de separação de enantiômeros em LMS sob condições lineares com os respectivos valores de pureza atingidos

\begin{tabular}{lllccc}
\hline Racemato & FEQ & Fase Móvel & $P_{E}$ & $P_{R}$ & Ref. \\
\hline Cetamina & MCTA & Etanol & 100 & 100 & 21 \\
$\alpha$-ionone & Ciclodextrina & Metanol/água & 100 & 100 & 89 \\
$\alpha$-ionone & Ciclodextrina & Metanol/água* & 100 & 51 & 89 \\
1-fenil-1-propanol & Chiralcel OB & Hexano/acetato de etila (95:5) & $>97$ & 100 & 90 \\
Base de Tröger & MCTA & Etanol & 98,8 & 98,6 \\
\hline
\end{tabular}

*Eluição gradiente. $\mathrm{P}_{\mathrm{E}}$ e $\mathrm{P}_{\mathrm{R}}$ estão definidos na Tabela 4

Tabela 7. Exemplos recentes de separação de enantiômeros em LMS sob condições não-lineares com os respectivos valores de pureza atingidos

\begin{tabular}{lllcc}
\hline Racemato & FEQ & Fase Móvel & $P_{E}$ & $P_{R}$ \\
\hline Binaftol & DNBPG-sílica & Heptano/isopropanol (72:28) & 99,1 & 98,9 \\
Guaifenesina & Chiralcel OD & Heptano/etanol (65:35) & 99,2 & 99,9 \\
1-fenil-1-propanol & Chiralcel OB & Hexano/acetato de etila (95:5) & $>95$ & $>98$ \\
1-fenoxi-2-propanol & Chiralcel OD & Hexano/isopropanol (90:10) & 100 & 100 \\
Base de Tröger & Chiralpak AD & Isopropanol & 99,97 & 98,89 \\
Fluoxetina & B-ciclodextrina & Metanol/triacetato de etilamina (60:40) & 92,5 & 90 \\
\hline
\end{tabular}


a exploração do potencial do LMS para este fim ${ }^{111}$. Desde então diversas empresas espalhadas pelo mundo têm focalizado seus trabalhos na produção de fases estacionárias quirais com elevado poder de resolução de misturas racêmicas ou até mesmo na montagem e comercialização de unidades LMS.

Como relatado por Rouhi ${ }^{112}$, um processo desenvolvido pela empresa americana Aerojet Fine Chemicals que operava satisfatoriamente com colunas de $50 \mathrm{~mm}$ de diâmetro em outubro de 2003 passou a operar com colunas de $200 \mathrm{~mm}$ de diâmetro em dezembro do mesmo ano. Em alguns meses, a produção passou de alguns quilogramas para $250 \mathrm{~kg}$. Sendo o processo LMS uma separação física, esta produção poderia alcançar quantidades em toneladas métricas, uma vez que a unidade LMS pode operar em qualquer escala.

Em Lexington (EUA), a Universal Pharma Technologies (UPT) - um empreendimento conjunto da UOP e a firma de desenvolvimento químico farmacêutico Pharma Eco - estão operando uma unidade LMS com capacidade de produção de 10 a 20 toneladas métricas por ano de enantiômeros puros. UPT tem operado com capacidade de 2 toneladas métricas desde 1998. No ano de 2001, a Bayer inaugurou uma unidade piloto em Leverkusen (Alemanha). A unidade possui capacidade de operação em torno de 5 toneladas métricas por ano. A indústria farmacêutica Belga UCB Pharma foi a primeira companhia a adotar uma unidade LMS em larga escala. A unidade foi instalada na Bélgica, em 1997, para produção de um fármaco (não revelado) e que ainda deve alcançar produção comercial. Fora da lista de companhias operando em larga escala estão a companhia japonesa Daicel - companhia especializada em prover colunas cromatográficas empacotadas utilizadas no sistema LMS - e a Novasep. Estas companhias operam unidades menores, de cerca de 1 tonelada métrica a poucas toneladas por ano, respectivamente ${ }^{111}$.

A grande vantagem da tecnologia LMS é sem dúvida o seu rápido desenvolvimento. A grande desvantagem ainda é o elevado custo de aquisição da tecnologia, que pode chegar a 15 milhões de dólares desde a efetivação da compra de uma unidade até o seu pleno funcionamento ${ }^{112}$

\section{PESQUISAS UTILIZANDO O CONCEITO DO LMS PARA SEPARAÇÃO DE ENANTIÔMEROS NO BRASIL}

De nosso conhecimento existe apenas uma unidade LMS operando no Brasil. Esta unidade (Figura 10) encontra-se localizada no Departamento de Processos Biotecnológicos (DPB) da Faculdade de Engenharia Química da Universidade Estadual de Campinas (UNICAMP) e conta com a colaboração do Laboratório de Síntese de Substâncias Orgânicas do Instituto de Química da UNICAMP. A primeira tese de Doutorado desenvolvida nesta unidade foi defendida em fevereiro de 2004 e mais cinco outros trabalhos de tese estão em andamento, sendo três em fase inicial. Este trabalho pioneiro gerou duas publicações, ainda como resultados preliminares, por Santos et al..$^{21}$ e Garcia et al. ${ }^{113}$.

Como resultado dos trabalhos realizados foram dominados diversos aspectos da tecnologia LMS, tais como a preparação de fases estacionárias quirais de diversos tipos, o empacotamento de colunas, o projeto das condições operacionais do LMS e a realização de corridas experimentais que demonstraram as vantagens inerentes ao leito móvel simulado, como os altos índices de purificação e a economia na utilização de dessorventes. Como etapas a serem desenvolvidas no futuro destacamos a investigação de fases estacionárias com menores quedas de pressão e a conseqüente utilização de maiores vazões e de concentrações da alimentação, ensejando a operação em condições francamente não lineares. A modelagem química das separações quirais é também uma meta importante, visando a previsão do comportamento da separação e a otimização do processo de separação.

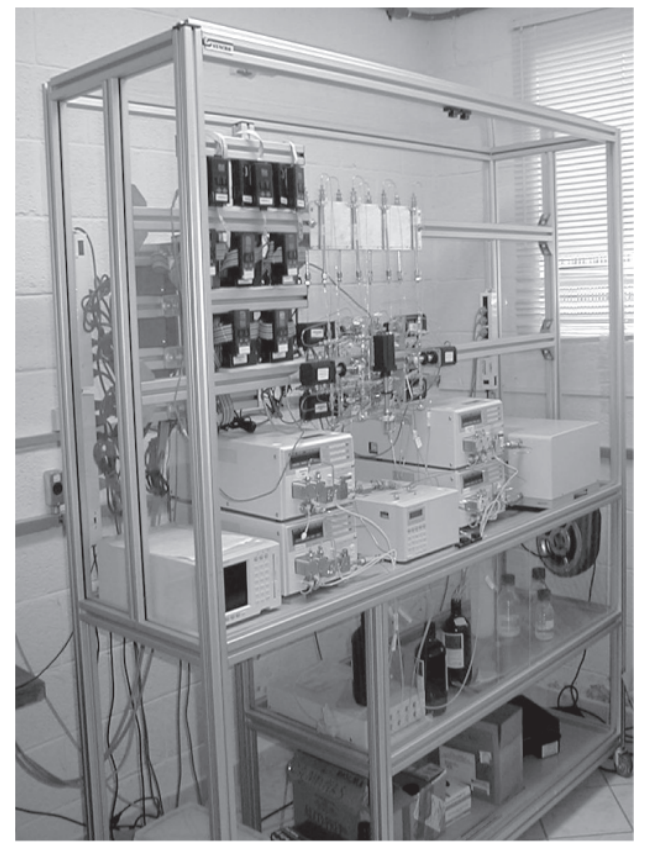

Figura 10. Unidade LMS localizada no Departamento de Processos Biotecnológicos da Faculdade de Engenharia Química, Universidade Estadual de Campinas

\section{CONCLUSÕES}

A tecnologia LMS para separação enantiomérica tem sido aplicada com sucesso em escala laboratorial e industrial desde a primeira aplicação realizada em 1992 por Negawa e Shoji, e vem sendo acrescida de desenvolvimentos importantes na última década. Grande parte do sucesso deve-se à melhoria nas técnicas de preparação das fases estacionárias quirais. As fases estacionárias quirais baseadas no recobrimento de sílica macro-porosa por derivados de polissacarídeos têm obtido maior sucesso em aplicações preparativas devido principalmente a altas capacidades de adsorção, seletividade e estabilidade. A quantidade e a qualidade das pesquisas utilizando a tecnologia LMS tem aumentado consideravelmente como decorrência de vantagens apresentadas frente às outras técnicas cromatográficas preparativas, como o menor consumo de líquido dessorvente e um melhor aproveitamento da fase estacionária. Atualmente estão relatadas produtividades de até $1,5 \mathrm{~kg}$ de enantiômero por $\mathrm{kg}$ de fase estacionária por dia em colunas de 80 $\mathrm{cm}$ de diâmetro interno utilizando $180 \mathrm{~kg}$ de fase estacionária.

O excelente desempenho de separação apresentado pela tecnologia LMS tem despertado interesse na indústria farmacêutica onde uma grande parte delas já possui unidades instaladas em suas dependências dedicadas a trabalhos de pesquisa e desenvolvimento de moléculas enantiomericamente puras.

\section{AGRADECIMENTOS}

À FAPESP, ao CNPq e à FAEPEX-Unicamp pelo apoio financeiro aos projetos em desenvolvimento nos respectivos laboratórios e às bolsas de estudos e pesquisas concedidas pela FAPESP (M. J. S. Carpes; V Veredas.) e CNPq (M. A. G. Santos; I. J. da Silva Jr.; C. C. Santana e, C. R. D. Correia). Aos assessores de Química 
Nova pelas sugestões apresentadas durante o processo de revisão do manuscrito.

\section{REFERÊNCIAS}

1. Wang, X.; Ching, C.-B.; J. Chromatogr., A 2004, 1035, 167.

2. Aboul-Enein, H. Y.; J. Chromatogr., A 2001, 906,185.

3. Maier, N., Franco, P., Linder, W.; J. Chromatogr., A 2001, 906, 3.

4. Juza, M.; Mazzotti, M.; Morbidelli, M.; Trends Biotechnol. 2000, 18, 108.

5. FDA's policy statement for the development of new stereoisomeric drugs; Chirality 1992, 4, 338

6. Chin-Joe, I.; PhD Thesis, Delft University of Technology, Delft, The Netherlands, 2002

7. Rekoske, J. A.; AIChE J. 2001, 47, 2.

8. Rouhi, A. M.; Chem. Eng. News 2003, 81, 45.

9. Francotte, E. R.; J. Chromatogr, A 2001, 906, 379.

10. Haginaka, J.; J. Pharm. Biomed. Anal. 2002, 27, 357.

11. Francotte, E. R.; J. Chromatogr, A 1994, 666, 565.

12. Miller, L.; Orihuela, C.; Fronek, R.; Murphy, J.; J. Chromatogr., A 1999, $865,211$.

13. Schramm, H.; Kaspereit, M.; Kienle, A.; Seidel-Morgenstern, A.; J. Chromatogr., A 2003, 1006, 77.

14. Haag, J.; Wouwer, V.; Lehoucq, S.; Saucez, P.; Control Eng. Pratice 2001, 9, 921 .

15. Schulte, M.; Strube, J.; J. Chromatogr., A 2001, 906, 399.

16. Francotte, E; Richert, P.; J. Chromatogr., A 1997, 769, 101.

17. Ching, C.-B.; Ruthven, D. M.; Chem. Eng. Sci. 1985, 40, 877.

18. Silva, V. M.; Minceva, M.; Rodrigues; A. E.; Ind. Eng. Chem. Res. 2004, 43, 4494.

19. Pais, L. S.; Loureiro, J. M.; Rodrigues; A. E.; J. Chromatogr., A 1998, 827, 215.

20. Chu, K. H.; Hashim, M. A.; The Chem. Eng. J. 1995, 56, 59.

21. Santos, M. A. G.; Veredas, V.; Silva Junior, I. J.; Correia, C. R. D.; Furlan, L. T.; Santana, C. C.; Braz. J. Chem. Eng. 2004, 21, 127.

22. Grill, C. M.; Miller, L.; Yan, T. Q.; J. Chromatogr., A 2004, 1026, 101.

23. Abel, S.; Mazzotti, M.; Morbidelli, M.; J. Chromatogr., A 2004, 1026, 47.

24. Minceva, M.; Pais, L. S.; Rodrigues, A. L.; Chem. Eng. Process. 2003, 42, 93.

25. Pais, L. S.; Loreiro, J. M.; Rodrigues, A. E.; Sep. Purif. Technol. 2000, 20,67

26. Lehoucq, S.; Wouwer, A. V.; Cavoy, E.; AIChE J. 2000, 46, 247.

27. Bubnik, Z.; Pour, V.; Gruberova, A.; Starhova, H.; Hinkova, A.; Kadlec, P.; J. Food Eng. 2004, 61, 509.

28. Azevedo, D. C. S; Rodrigues, A. E.; AIChE J. 2001, 47, 2042.

29. Mun, S.; Xie, Y.; Wang, N.-H. L.; AIChE J. 2003, 49, 2039.

30. Mun, S.; Xie, Y.; Wang, N.-H. L.; Ind. Eng. Chem. Res. 2003, 3129

31. Cremasco, M. A.; Wang, N.-H. L; Braz. J. Chem. Eng. 2003, 20, 181.

32. Houwing, J.; Jensen, T. B.; van Hateren, S. H.; Billiet, H. A. H.; van der Wielen, L. A. M.; AIChE J. 2003, 49, 665.

33. Houwing, J.; Billiet, H. A. H.; van der Wielen, L. A. M.; AIChE J. 2003, $49,1158$.

34. Lucena, S. L.; Rosa, P. T. V.; Furlan, L. T.; Santana, C. C. Em Engineering and Manufacturing for Biotechnology 4; Hofman, M.; Thonart, P., eds.; Kluwer Academic Publishers, MA, 2001, p. 325.

35. Lee, H.-J.; Xie, Y.; Koo, Y.-M.; Wang, N.-H. L.; Biotechnol. Prog. 2004, 20, 179.

36. Tabela adaptada de Ahuja, S.; Chiral Separations by Chromatography, Oxford University Press: New York, 2003.

37. Henderson, G. M.; Rule, H. G.; J. Chem. Soc. 1939, 1568.

38. Dalgliesh, C. E.; J. Chem. Soc. 1952, 3940.

39. Gil-Av, E.; Feibush, B.; Charless, R.; Tetrahedron Lett. 1966, 10, 1009

40. Davankov, V. A.; Rogozhin, S. V.; J. Chromatogr. 1971, 60, 1971.

41. Wulff, G.; Sarhan, A.; Angew. Chem., Int. Ed. 1972, 11, 341.

42. Hesse, G.; Hagel, R. A.; Chromatographia 1973, 6, 277.

43. Stewart, K. K.; Doherty, R. F.; Proc. Natl. Acad. Sci. U. S. A. 1973, 70, 2850 .

44. Blaschke, G.; Chem. Ber. 1974, 107, 232

45. Gokel, G. W.; Timko, J. M.; Cram, D. J.; J. Chem. Soc., Chem. Commun. 1975, 10, 394

46. Pirkle, W. H.; House, D. W.; J. Org. Chem. 1979, 44, 1957.

47. Okamoto, Y.; Suzuki, K.; Ohta, K.; Hatada, K.; Yuki, H.; J. Am. Chem. Soc. 1979, 101, 4763

48. Allenmark, S.; Bomgren, B.; J. Chromatogr., A 1982, 237, 473.

49. Hermansson, J.; J. Chromatogr., A 1983, 269, 71

50. Armstrong, D. W.; J. Liq. Chromatogr. 1984, 7, 353.

51. Armstrong, D. W.; Liu, Y. B.; Ekborg-Ott, K. H.; Chirality 1995, 7, 474.
52. Andersson, M.; Aslan, D.; Clarke, A.; Roeraade, J.; Hagman, G.; J. Chromatogr., A 2003, 1005, 83.

53. Pirkle, W. H.; Porchapsky, T. C.; Chem. Rev. 1989, 89, 347.

54. Okamoto, Y.; Kaida, Y.; J. Cromatogr. A 1994, 666, 403.

55. Rizzi, A. M.; J. Chromatogr. 1989, 478, 71.

56. Rizzi, A. M.; J. Chromatogr. 1989, 478, 87.

57. Jacobson, C. S.; Seidel-Morgenstern, A.; Guiochon, G.; J. Chromatogr. 1993, 637, 13.

58. Seidel-Morgenstern, A.; Guiochon, G.; Chem. Eng. Sci. 1993, 48, 2787; Migliorini, C.; Mazzotti, M.; Zenoni, G.; Morbidelli, M.; AIChE J. 2002, $48,69$.

59. Tachibana, K.; Ohnishi, A.; J. Chromatogr., A 2001, 906, 127; Wang, T.; Wenslow, J. R. M.; J. Chromatogr., A 2003, 1015, 99.

60. Bonato, P. S.; Bortocan, R.; Gaitani, C. M.; Paias, F. O.; Iha, M. H.; Lima, R. P; J. Braz. Chem. Soc. 2002, 13, 190.

61. Cavazzini, A.; Kaczmarski, K.; Szabelski, P.; Zhou, D.; Liu, X.; Guiochon, G.; Anal. Chem. 2001, 73, 5704; A despeito das recomendações para o uso de eluentes não polares contendo apenas pequenas proporções de eluentes polares, tais como metanol, etanol ou isopropanol, as fases estacionárias polissacarídicas apresentam-se relativamente estáveis em metanol, etanol ou isopropanol puros (Profa. Q. Cass, comunicação pessoal). No caso do triacetato de celulose microcristalina (MCTA) existem precedentes para uso de etanol e metanol puros. Para maiores detalhes, ver Silva Jr., I. J.; Santos, M. A. G.; Veredas, V; Santana, C. C.; Sep. Purif. Technol. 2005, 43, 103.

62. Andersson, S.; Allenmark, S.; Möller, P.; Persson, B.; Sanchez, D.; J. Chromatogr, A 1996, 741, 23.

63. Skogsberg, U.; Händel, H.; Sanchez, D.; Albert, K.; J. Chromatogr., A 2004, 1023, 215.

64. Skogsberg, U; PhD Thesis, Göteborg University, Sweden, 2001.

65. Francotte, E.; Huynh, D.; J. Pharm. Biomed. Anal. 2002, 27, 421.

66. Nicoud, R. M.; The Separation of Optical Isomers by Simulated Moving Bed Chromatography, Pharmaceutical Technology Europe, 1999.

67. Pais, L. S.; Loreiro, J. M.; Rodrigues, A. E.; Chem. Eng. Sci. 1997, 52 , 245

68. Nicoud, R. M. In Handbook of Bioseparations; Ahuja, S., ed.; Academic Press: San Diego, 2000, p. 475.

69. Mazzotti, M.; Storti, G.; Morbidelli, M.; J. Chromatogr., A 1997, 769, 3

70. Yu, H. W.; Ching, C. B.; AIChE J. 2002, 48, 2240.

71. Lucena. S.; Tese de Doutorado, Universidade Estadual de Campinas, Brasil, 1999.

72. Storti, G.; Mazzotti, M.; Morbidelli, M.; Carrà, S.; AIChE J. 1993, 39, 471.

73. Azevedo, D. C. S.; Rodrigues, A.; AIChE J. 1999, 45, 956.

74. Ma, Z.; Wang, N.-H. L; AIChE J. 1997, 43, 2488.

75. Migliorini, C.; Mazzotti, M.; Zenoni, G.; Morbidelli, M.; J. Chromatogr., A 1998, 827, 161

76. Xie, Y.; Hritzko, B.; Chin, C. Y.; Wang, N.-H. L; Ind. Eng. Chem. Res. 2003, $42,4055$.

77. Xie, Y.; Farrenburg, C. A.; Chin, C. Y.; Mun, S.; Wang, N.-H, L.; AIChE J. 2003, 49, 2850 .

78. Rodrigues, A. E.; Pais, L. S.; Sep. Sci. Technol. 2004, 39, 245.

79. Francotte, E.; Richert, P.; Mazzotti, M.; Morbidelli, M.; J. Chromatogr., A 1998, 796, 239

80. Charton, F.; Nicoud, R. M.; J. Chromatogr., A 1995, 702, 97.

81. Negawa, M.; Shoji, F.; J. Chromatogr. 1992, 590, 113.

82. Biressi, G.; Lundemann-Hombourger, O.; Mazzotti, M.; Nicoud, M.; Morbidelli, M.; J. Chromatogr., A 2000, 876, 3.

83. Silva Junior, I. J.; Dissertação de Mestrado, Universidade Estadual de Campinas, Brasil, 2003.

84. Miller, L.; Grill, C.; Yan, T.; Dapremont, O.; Huthmann, E.; Juza, M.; J. Chromatogr., A 2003, 1006, 267.

85. Guiochon, G.; Lin, B.; Modeling for Preparative Chromatography, Academic Press: San Diego, 2003.

86. Gritti, F.; Guiochon, G.; J. Colloid Interface Sci. 2003, 264, 43.

87. Migliorini, C.; Mazzotti, M.; Zenoni, G.; Pedeferri, M.; Morbidelli, M.; AIChE J. 2000, 46, 1530.

88. Kaspereit, M.; Jandera, P.; Škavrada, M.; Seidel-Morgenstern, A.; J Chromatogr., A 2002, 944, 249.

89. Abel, S.; Mazzotti, M.; Morbidelli, M.; J. Chromatogr., A 2002, 944, 23.

90. Khattabi, S.; Cherrak, D. E.; Mihlbachler, K.; Guiochon, G.; J. Chromatogr., A 2000, 893, 307.

91. Pedeferri, M. P.; Zenoni, G.; Mazzotti, M.; Morbidelli, M.; Chem. Eng. Sci. 1999, 54, 3735 .

92. Heuer, C.; Küsters, E.; Plattner, T.; Seidel-Morgenstern, A.; J. Chromatogr., A 1998, 827, 175

93. Mihlbachler, K.; Jupke, A.; Seidel-Morgenstern, A.; Schmidt-Traub, H.; Guiochon, G.; J. Chromatogr., A 2002, 944, 3.

94. Yu, H. W.; Ching, C. B.; Adsorption 2003, 9, 213. 
95. Lorenz, H.; Sheehan, P.; Seidel-Morgenstern, A.; J. Chromatogr., A 2001, 908, 201

96. Kaspereit, M.; Lorenz, H.; Seidel-Morgenstern, A. In Fundamentals of Adsorption 7; Kaneko, K.; Kanoh, H., eds.; International Adsorption Society: Japan, 2002, p 101.

97. Pynnonen, B.; J. Chromatogr., A 1998, 827, 143.

98. Peper, S.; Lübbert, M.; Johannsen, M.; Brunner, G.; Sep. Sci. Tecnhol. 2002 37, 2545.

99. Mazzotti, M.; Storti, G.; Morbidelli, M.; J. Chromatogr., A 1997, 786, 309.

100. Migliorini, C.; Wendlinger, M.; Mazzotti, M.; Morbidelli, M.; Ind. Eng. Chem. Res. 2001, 40, 2606.

101. Antos, D.; Seidel-Morgenstern, A.; Sep. Sci. Technol. 2002, 37, 1469.

102. Nicolaos, A.; Muhr, L.; Gotteland, P.; Nicoud, R.; Bailly, M.; J. Chromatogr., A 2001, 908, 71.

103. Nicolaos, A.; Muhr, L.; Gotteland, P.; Nicoud, R.; Bailly, M.; J. Chromatogr., A 2001, 908, 87.
104. Zang, Y.; Wankat, P.; Ind. Eng. Chem. Res. 2002, 41, 2504

105. Andersson, S.; Allenmark, S. G.; J. Biochem. Biophys. Methods 2002, 54, 11

106. Ludemann-Hombourger, O.; Nicoud, R. M.; Bailly, M.; Sep. Sci. Technol. 2000, 35, 1829.

107. Ludemann-Hombourger, O.; Pigorini, G.; Nicoud, R. M.; Ross, D. S.; Terfloth, G.; J. Chromatogr., A 2002, 947, 59.

108. Pais, L. S.; Rodrigues, A. E.; J. Chromatogr., A 2003, 1006, 33

109. Zhang, Z.; Mazzotti, M.; Morbidelli, M.; J. Chromatogr., A 2003, 1006, 87.

110. Zhang, Z.; Mazzotti, M.; Morbidelli, M.; Korean J. Chem. Eng. 2004, 21, 454.

111. McCoy, M.; Chem. Eng. News 2000, 78, 17.

112. Rouhi, A. M.; Chem. Eng. News 2004, 82, 47.

113. Garcia, A. L. L.; Carpes, M. J. S.; Oca, A. C. B. M.; Santos, M. A. G.; Santana, C. C.; Correia, C. R. D.; J. Org. Chem. 2005, 70, 1050. 